\title{
Surgical bypass and permanent iodine-125 seed implantation vs. surgical bypass for the treatment of pancreatic head cancer
}

\author{
ZHENJIANG ZHENG, YINGLONG XU, SHU ZHANG, GUANGCHUN PU and CHI CUI \\ Department of General Surgery, The Third People's Hospital of Chengdu, \\ The Second Affiliated Hospital of Chengdu, Chongqing Medical University, Chengdu, Sichuan 610031, P.R. China
}

Received September 8, 2015; Accepted February 13, 2017

DOI: $10.3892 / \mathrm{ol} .2017 .6495$

\begin{abstract}
The present study aimed to investigate the efficacy and safety of Iodine-125 $\left({ }^{125} \mathrm{I}\right)$ seed implantation in the treatment of locally advanced unresectable pancreatic head cancer. A prospective nonrandomized study was performed using data collected from patients between January 2009 and December 2012. A total of 34 patients underwent surgical bypass and permanent ${ }^{125}$ I seed implantation (group A), and 32 patients underwent biliary and gastric bypass (group B). The preoperative variables, operative data, postoperative complications and follow-up information were examined. No significant differences were identified in clinical characteristics, mortality, morbidity and length of hospital stay between the two groups. Tumor responses were significantly different between between patients in group A and B (partial response, 56 vs. $0 \%, \mathrm{P}<0.001$; progression, 24 vs. $84 \%, \mathrm{P}=0.013)$. The time until disease progression was significantly longer in group A compared to group $\mathrm{B}(8 \pm 1$ vs. $5 \pm 2$ months; $\mathrm{P}<0.001)$. The median survival time was significantly longer in group A compared to group B (11 vs. 7 months; $\mathrm{P}<0.001$ ). The quality of life was improved significantly in group A compared to group B. In the first month following surgery, pain scores were improved $(24 \pm 10$ vs. 54 \pm 19 ; $\mathrm{P}<0.001)$. Following repeated measure analysis, pain scores were significantly lower in group A compared to group $\mathrm{B}(\mathrm{P}<0.05)$ at 9 months following surgery. The results of the present study suggest that ${ }^{125}$ I seed implantation is feasible, safe and effective for the treatment of unresectable pancreatic head cancer.
\end{abstract}

Correspondence to: Dr Shu Zhang, Department of General Surgery, The Third People's Hospital of Chengdu, The Second Affiliated Hospital of Chengdu, Chongqing Medical University, 82 Qinglong Street, Chengdu, Sichuan 610031, P.R. China

E-mail: zhangshu_1961@sina.com

Key words: brachytherapy, pancreatic cancer, iodine-125, pain measurement

\section{Introduction}

In the United States, 46,420 patients were diagnosed with and 39,590 patients succumbed to pancreatic cancer in 2014 (1). The overall 5-year relative survival rate for patients with pancreatic cancer was $6 \%$ (1). At present, surgery is the only curative therapeutic approach. However, only 10-15\% of patients with pancreatic cancer are considered suitable candidates for resection at the time of diagnosis (2). The palliative surgical procedures, including splanchnicectomy, biliary bypass and gastric bypass are frequently performed, with a median survival time of 6 months $(3,4)$.

To improve the therapeutic effectiveness and reduce side effects of treatments, the use of novel treatment techniques, including intraoperative interstitial brachytherapy, have been investigated. In 1934, the implantation of a radium needle was utilized in seven patients with pancreatic cancer (5) with one of these patients surviving up to 2 years. Hilaris and Rousiss (6) reported one of the earliest experiences of radioactive Iodine-125 $\left.{ }^{125} \mathrm{I}\right)$ seed implantation for the treatment of pancreatic cancer in 98 patients. The median survival time was 7 months, and one patient survived up to 5 years (6). Subsequent case studies using ${ }^{125} \mathrm{I}$ as the implanted isotope have reported median survival times between 7-14 months (7-9).

Patients with pancreatic cancer have been demonstrated to benefit from ${ }^{125}$ I seed implantation $(10,11)$ However, a controlled study has not been previously reported. To investigate the efficacy and safety of ${ }^{125}$ I seed implantation in the treatment of locally advanced unresectable pancreatic head cancer, a prospective nonrandomized study was performed.

\section{Materials and methods}

Patients. A consecutive series of 68 patients with locally advanced unresectable pancreatic head carcinoma diagnosed following surgical examination were enrolled in the present study between January 2009 and December 2012 at The Third People's Hospital of Chengdu (Chengdu, China). Among them, 35 patients underwent a combination of surgical bypass (biliary and gastric bypass) and permanent ${ }^{125}$ I seed implantation (group A), and 33 patients underwent biliary and gastric bypass (group B). The selection of treatment method used was based on the decision of each patient. Prior to making a 
decision, the patients were appropriately informed about treatment methods and the possible complications.

Inclusion criteria were a Karnofsky performance status score (12) of $\geq 70$, an anticipated survival of $\geq 3$ months, ability to undergo follow-up assessment and no history of previous anticancer treatment. Exclusion criterion was the existence of distant metastases. The current study was approved by the Ethics Committee of The Third People's Hospital of Chengdu and written informed consent was obtained from all patients. Data collected prior to surgery included demographics, physical examination results, blood test results, abdominal computed tomography (CT), pain score and quality of life (QOL) assessment. The largest diameter reported from the CT report was defined as the tumor size.

Definitions. Locally advanced unresectable pancreatic head carcinoma was defined as pathologically proven local invasion of major visceral vessels and no evidence of metastases demonstrated during explorative surgery (13). To diagnose and predict the severity of pancreatitis, the 2012 revision of the Atlanta Classification of acute pancreatitis was used (14). Pancreatic fistula was defined as a drain output of any measurable volume of fluid on or following postoperative day 3 with an amylase content $>3$ times the serum amylase activity (15). Biliary fistula was defined as persistence of biliary drainage for $>5$ days (16). Delayed gastric emptying (DGE) was defined as nasogastric drainage for $>10$ days or a delay from regular diet until 14 days postoperatively (17).

Technique of ${ }^{125}$ I implantation. At the time of exploratory laparotomy, elevation of the duodenum (Kocher procedure) was necessary in order to accurately assess the posterior margin of the tumor in the pancreatic head. The tumor size was determined subsequent to measuring three mutually perpendicular dimensions of the tumor (18). The implanted volume included the tumor size plus $0.5 \mathrm{~cm}$ of peripheral tissue. The expected number of implanted seeds was calculated according to the Cevc equation (19).

Following the histologically confirmed diagnosis of pancreatic carcinoma using fine needle aspiration biopsy, the needles (18-gauge, hollow, stainless steel) were implanted into the tumor and spaced at parallel intervals of $1.0 \mathrm{~cm}$, extending $\geq 0.5 \mathrm{~cm}$ beyond the margins of the mass. The depth of needle placement was monitored by feeling the tip of the needle with the operating finger of the radiation oncologist. If bile, blood, or pancreatic juice issued from the needle when the stylet was withdrawn therefrom, the needle was retracted a number of millimeters and the stylet was left in place until the time of ${ }^{125} \mathrm{I}$ seed insertion (20). A Mick-applicator (Mick Radio-Nuclear Instruments, Inc., Mount Vernon, NY, USA) was then attached to each needle and the seeds (Shanghai Xinke Pharmaceutical Co., Ltd., Shanghai, China) were implanted at $1.0 \mathrm{~cm}$ intervals while withdrawing the needle. To minimize the dose to the adjacent stomach and bowel and prevent pancreatic fistula, a segment of omentum was placed over the implanted surface of the pancreas. A median number of 27 seeds/patient (range, 20-39 seeds) were implanted. During the surgery, surgeons wore lead aprons and lead gloves. The exposure dose was measured using a personal dosimeter worn on the chest.
Surgical procedure. All the patients underwent retrocolic gastrojejunostomy and choledochojejunostomy regardless of ${ }^{125} \mathrm{I}$ implantation. For the patient without the symptoms and signs of duodenal obstruction and jaundice, prophylactic bypass was performed. A total of 7 patients with severe malnutrition underwent feeding jejunostomies. Patients in group A received somatostatin analogues in order to prevent pancreatitis and pancreatic fistula development. All patients were recommended to undergo postoperative chemotherapy or radiotherapy. For different reasons, only eight patients received chemotherapy consisted of gemcitabine. The other patients refused to receive the postoperative treatment.

Follow-up. Patients were observed monthly during the first year following surgery and then at three month intervals. Evaluations during the follow-up included physical examinations, blood tests, chest X-ray, abdominal CT scan, QOL and pain score. During the follow-up, collection of the patients' opinions was performed by a doctor who was blinded to the study. The mean follow-up time was $11 \pm 6$ months. Survival time was defined as the time span between initial treatment and mortality or loss of contact. Compliance was defined as the number of patients who completed the questionnaire expressed as a proportion of the number of patients alive.

Response criteria. Response was evaluated according to the World Health Organization criteria (21). A complete response (CR) was defined as the disappearance of all known lesions, without appearance of new lesions for $\geq 4$ weeks. A partial response (PR) was defined as $\geq 50 \%$ decrease in the maximum transverse tumor measurements, with no appearance of new lesions on two observations 4 weeks apart. No change (NC) was defined as $<50 \%$ decrease and $<25 \%$ increase in the size of measurable lesions. Progressive disease (PD) was defined as $\geq 25 \%$ increase in the size of one or more measurable lesions or the appearance of new lesions. Time to progression was determined as the interval between the date of first treatment and the date at which PD was first observed.

Quality of life. For prospective measurement of QOL, the standard Chinese version of the European Organization for Research and Treatment of Cancer Quality of Life Core Questionnaire (QLQ-C30; version 3.0) was used (22). The QLQ-C30 consists of 30 items pertaining to 5 functional scales, symptoms and global quality of life (22). Its feasibility has previously been validated for patients in China (23).

Baseline measurements were performed prior to surgery. Subsequent questionnaires were completed at 1, 3, 6, 9 and 12 months following surgery. In accordance with van Heek et al (24), the global health status, physical and emotional functioning and all gastrointestinal (GI) symptom scales of the QLQ-C30 provide the appropriate information. Therefore, an overall digestive symptom scale including nausea and vomiting, appetite loss, constipation and diarrhea was created.

Pain score. Pain intensity was quantified using a specially designed pain score (25), including two subjective items, the patient's self-estimation of intensity of pain using a visual analog scale and the frequency of pain attacks, and two objective 
Table I. Clinicopathological characteristics of patients with locally advanced unresectable pancreatic head carcinoma.

\begin{tabular}{|c|c|c|c|}
\hline \multirow[b]{2}{*}{ Clinicopathological characteristics } & \multicolumn{2}{|c|}{ Value } & \multirow[b]{2}{*}{ P-value } \\
\hline & Group A, n=34 & Group B, $n=32$ & \\
\hline Age, years ${ }^{\mathrm{a}}$ & $56 \pm 9$ & $57 \pm 10$ & 0.878 \\
\hline \multicolumn{4}{|l|}{$\operatorname{Sex}^{\mathrm{b}}$} \\
\hline Male & $21(62)$ & $18(56)$ & \multirow[t]{2}{*}{0.649} \\
\hline Female & $13(38)$ & $14(44)$ & \\
\hline \multicolumn{4}{|l|}{ Preoperative symptoms ${ }^{\mathrm{b}}$} \\
\hline Abdominal pain & $25(74)$ & $27(84)$ & 0.281 \\
\hline Jaundice & $32(94)$ & $31(97)$ & $>0.999$ \\
\hline Weight loss & $31(91)$ & $28(88)$ & 0.705 \\
\hline $\mathrm{KPS}^{\mathrm{a}}$ & $81 \pm 7$ & $78 \pm 6$ & 0.107 \\
\hline Bilirubin, $\mathrm{mg} / \mathrm{dl}^{\mathrm{a}}$ & $15 \pm 5$ & $14 \pm 6$ & 0.792 \\
\hline CA19-9a & $567 \pm 286$ & $600 \pm 307$ & 0.768 \\
\hline \multicolumn{4}{|l|}{ TNM Stage ${ }^{b}$} \\
\hline T3N0-1M0 & $11(32)$ & $15(47)$ & \multirow{2}{*}{0.228} \\
\hline T4N0-1M0 & $23(68)$ & $17(53)$ & \\
\hline Tumor size, $\mathrm{mm}^{\mathrm{a}}$ & $43 \pm 6$ & $42 \pm 6$ & 0.566 \\
\hline
\end{tabular}

Data are presented as a mean \pm standard deviation or ${ }^{b}$ number $(\%)$. Group A patients underwent a combination of surgical bypass (biliary and gastric bypass) and permanent Iodine-125 seed implantation whereas patients in group B underwent biliary and gastric bypass only. KPS, Karnofsky performance status scale; CA, cancer antigen.

items, analgesic medication taken and the time periods of inability to work. The sum of the median values divided by 4 provided the final pain score.

Statistical analysis. Data are expressed as the mean \pm standard deviation or number and percentage. All statistical analyses were performed with SPSS (version 16.0; SPSS Inc., Chicago, IL, USA). $\chi^{2}$ or Fisher's exact tests were applied for categorical data and the Mann-Whitney $U$ test was used for numerical data. The Kaplan-Meier estimator method was used to analyze survival and levels of significance were determined with the log-rank test. $\mathrm{P}<0.05$ was considered to indicate a statistically significant difference.

\section{Results}

Study population. In group A, one patient was uncontactable during the follow-up. In group B, one patient was excluded from the analysis as the final pathology of the intraoperative specimen revealed a benign tumor. From the remaining 66 patients, 34 patients $(52 \%)$ underwent a combination of surgical bypass and permanent ${ }^{125} \mathrm{I}$ seed implantation, and 32 patients $(48 \%)$ underwent biliary and gastric bypass. The characteristics of the patients included in the study were similar across the two groups (Table I).

Postoperative complications and hospitalization stay. Mortality, morbidity and length of hospital stay are described in Table II. No mortality occurred during the perioperative period in the two groups. In group A, one patient had mild acute pancreatitis that was resolved with the use of somatostatin analogues. The incidence of DGE was not significantly influenced by ${ }^{125} \mathrm{I}$ seed implant. All patients with postoperative DGE were successfully treated conservatively. There were two pancreatic fistulas in group A, and one biliary and one GI fistula in group B. All the fistulas were treated without surgery. In each group, one patient required re-exploration for significant anastomotic bleeding. The duration of stay in hospital was $15 \pm 4$ days in group $A$ and $13 \pm 3$ days in group $\mathrm{B}(\mathrm{P}=0.104)$. During the follow-up, two patients in group A were diagnosed with gastric ulcer. In addition, one patient in group A had two seeds and another patient had three seeds that migrated to the liver.

Response. The tumor responses are presented in Table III. In group A, there were no cases of CR. A total of 19 patients presented with PR and NC was observed in 7 patients. PD was observed in 8 patients, and all presented with extra-pancreatic metastases. In addition, 6 patients presented with local progression with increase in the size of the primary tumor mass. In group $B$, the overall response rate was $0 \%$. The tumor was rated stable in 5 patients, and the other patients developed extrapancreatic metastases and simultaneous increase in the size of the pancreatic mass. The mean time until disease progression was signifi-

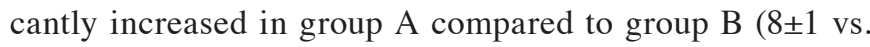
$5 \pm 2$ months; $\mathrm{P}<0.001)$.

Survival. The median survival time was significantly longer in group A compared to the patients in group B (11 vs. 7 months; $\mathrm{P}<0.001$ ). (Fig. 1). The 1 and 2-year survival rates were 50 and $12 \%$, respectively in group $\mathrm{A}$, as opposed to 19 and $0 \%$, respectively in group $B$. 
Table II. Postoperative complications and length of hospital stay of patients with locally advanced unresectable pancreatic head carcinoma.

\begin{tabular}{|c|c|c|c|}
\hline \multirow[b]{2}{*}{ Postoperative characteristics } & \multicolumn{2}{|c|}{ Value } & \multirow[b]{2}{*}{ P-value } \\
\hline & Group A, n=34 & Group B, n=32 & \\
\hline Pancreatitis $^{\mathrm{a}}$ & $1(3)$ & $0(0)$ & 1.0 \\
\hline GI bleeding ${ }^{\mathrm{a}}$ & $1(3)$ & $1(3)$ & 1.0 \\
\hline Pancreatic fistula $^{a}$ & $2(6)$ & $0(0)$ & 0.493 \\
\hline GI fistula ${ }^{a}$ & $0(0)$ & $1(3)$ & 0.493 \\
\hline Biliary fistula $^{a}$ & $0(0)$ & $1(3)$ & 0.493 \\
\hline $\mathrm{DGE}^{\mathrm{a}}$ & $5(15)$ & $2(6)$ & 0.427 \\
\hline Gastric ulcer ${ }^{\mathrm{a}}$ & $2(6)$ & $0(0)$ & 0.493 \\
\hline Length of hospital stay, days ${ }^{b}$ & $15 \pm 4$ & $13 \pm 3$ & 0.104 \\
\hline
\end{tabular}

Data are presented as anumber $(\%)$ or ${ }^{b}$ mean \pm standard deviation. Group A patients underwent a combination of surgical bypass (biliary and gastric bypass) and permanent Iodine-125 seed implantation whereas patients in group B underwent biliary and gastric bypass only. GI, gastrointestinal; DGE, delayed gastric emptying.

Quality of life. Compliance with questionnaire completion was comparable in the two groups (Table IV). Data on the QOL scales from the questionnaires were plotted graphically. Representative graphs are illustrated in Fig. 2 for each aspect of QOL. Prior to surgery, the patients in the two groups were comparable with respect to all scales. At 1 month following surgery, the two groups revealed a significant decrease in physical functioning compared to the preoperative status, but this had returned to preoperative values by 3 months' post-surgery. There were no significant changes in emotional functioning following surgery in either of the two groups. Global health status decreased following surgery in group B, however this decrease was not statistically significant. Global health status decreased in group A at 1 month following surgery. This values of this status improved between 3 and 6 months following surgery, and 6 months later it had returned to the preoperative status. The digestive symptoms were significantly more pronounced following the two surgical procedures.

Pain score. Fig. 3 illustrates a graphic description of the pain scores. No significant differences were observed in pain intensity prior to surgery between the two groups. The pain scores were stable over the course of the study for patients in group B. For patients in group A, a significant reduction was observed in pain scores that persisted for 9 months following surgery. At one month following surgery, the pain score indicated a $51 \%$ reduction from the baseline in group A $(49 \pm 20$ vs. $24 \pm 10$, respectively; $\mathrm{P}<0.001)$. A total of 3 patients with severe pain who were completely relieved from pain had no pain recurrence prior to mortality.

\section{Discussion}

In the present study, 3 and $6 \%$ patients suffered from pancreatitis and pancreatic fistulas following surgery in group A, respectively. To minimize postoperative complications, certain measures are used, including intraoperative ultrasound

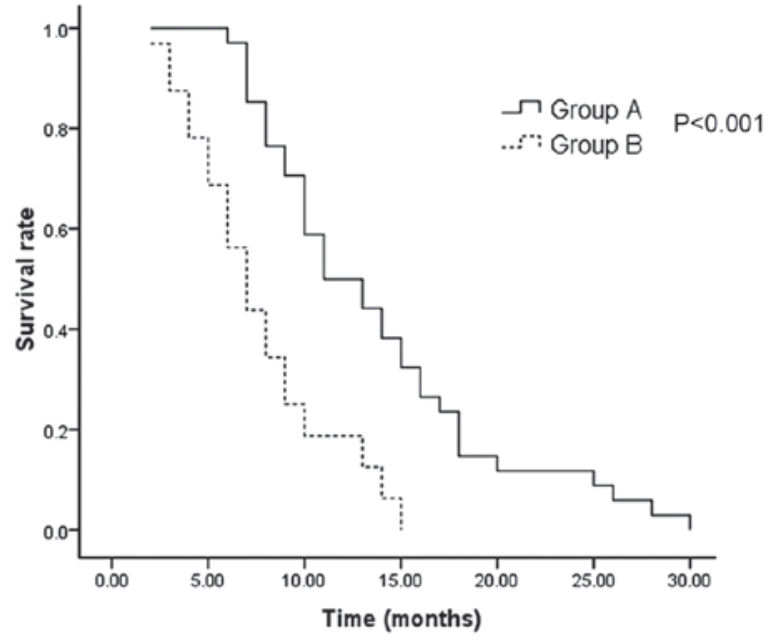

Figure 1. Comparison of overall survival time between two groups of patients with locally advanced unresectable pancreatic head carcinoma. Group A patients underwent a combination of surgical bypass (biliary and gastric bypass) and permanent Iodine-125 seed implantation whereas patients in group B underwent biliary and gastric bypass only.

guidance, suturing of pinholes, a segment of omentum placed over the implanted surface of the pancreas and somatostatin analogue treatment following surgery. There was no statistically significant difference in morbidity rates between the two groups. It was demonstrated that the implantation of ${ }^{125}$ I seeds did not increase the duration of hospital stay. In addition, the results of the present study suggested that ${ }^{125}$ I seed implantation for unresectable pancreatic head cancer is feasible and safe.

Ma et al (26) revealed that ${ }^{125}$ I seed implantation effectively inhibited pancreatic tumor growth and reduced tumor volume. ${ }^{125}$ I irradiation-induced apoptosis and DNA hypomethylation are two important mechanisms underlying the therapeutic effect of low-energy ${ }^{125}$ I seed implantation. In the present study, it was identified that ${ }^{125}$ I seed implantation provided more improved tumor responses, however the CR rate was identified to be $0 \%$ in group A. Zou et al (27) demonstrated 
Table III. Response to treatment of patients with locally advanced unresectable pancreatic head carcinoma.

Value

\begin{tabular}{lccc} 
Response & Group A $(\mathrm{n}=34)$ & Group B $(\mathrm{n}=32)$ & P-value \\
\hline Complete $^{\mathrm{a}}$ & $0(0)$ & $0(0)$ & 0.806 \\
Partial $^{\mathrm{a}}$ & $19(56)$ & $0(0)$ & 0.000 \\
No change $^{\mathrm{a}}$ & $7(21)$ & $5(16)$ & 0.427 \\
Progression $^{\mathrm{a}}$ & $8(24)$ & $27(84)$ & 0.013 \\
Time to progression, months $^{\mathrm{b}}$ & $8 \pm 1$ & $5 \pm 2$ & $<0.0001$ \\
\hline
\end{tabular}

Data are presented as ${ }^{a}$ number $(\%)$ or ${ }^{\mathrm{b}}$ mean \pm standard deviation. Group A patients underwent a combination of surgical bypass (biliary and gastric bypass) and permanent Iodine-125 seed implantation whereas patients in group B underwent biliary and gastric bypass only.
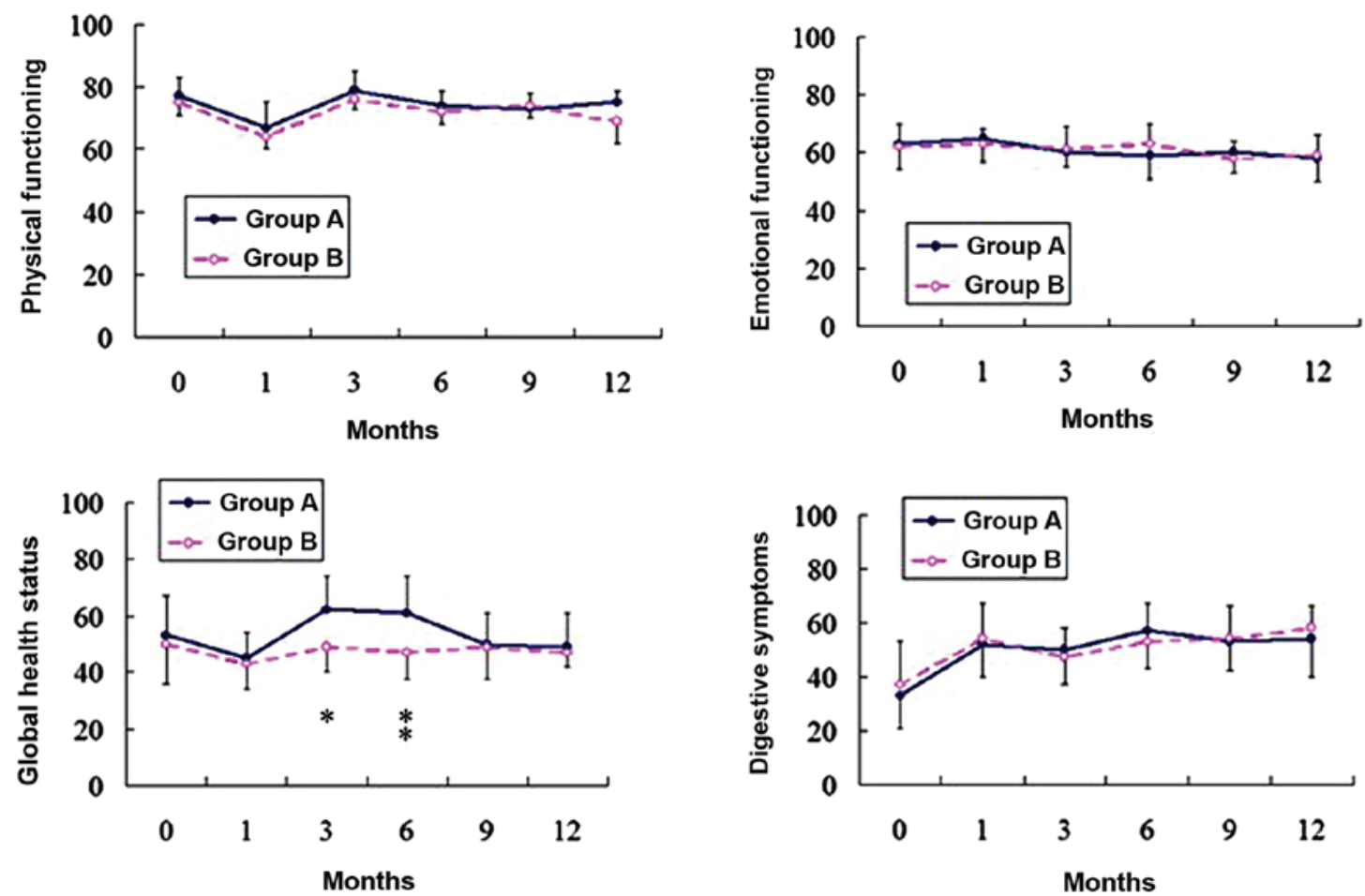

Figure 2. Comparison of representative scales of quality of life between two groups of patients with locally advanced unresectable pancreatic head carcinoma. Statistical significance are indicated as ${ }^{*} \mathrm{P}<0.001$ and ${ }^{* *} \mathrm{P}=0.003$ for global health status. Error bars indicate standard deviation. Group A patients underwent a combination of surgical bypass (biliary and gastric bypass) and permanent Iodine-125 seed implantation whereas patients in group B underwent biliary and gastric bypass only.

that intraoperative radiofrequency ablation combined with ${ }^{125}$ I seed implantation is an effective procedure for the treatment of unresectable pancreatic cancer. The rate of CR and PR was 21.8 and $56.3 \%$, respectively. Jin et al (28) performed a study on 22 patients with advanced pancreatic cancer who underwent endoscopic ultrasound-guided interstitial implantation of ${ }^{125} \mathrm{I}$ seeds combined with routine gemcitabine-based fluorouracil chemotherapy. Rates of complete and partial remission in the 22 patients were reported as 0 and $13.6 \%$, respectively. The lower rate of overall response was attributed to 18 patients with tumor stage III-IV, according to the International Union Against Cancer (UICC) classifications for pancreatic cancer set up in 2002 (29).
In the present study, it was demonstrated that ${ }^{125} \mathrm{I}$ seed implantation was beneficial for the extension of survival. Wang et al (11) reported that the median survival time for ${ }^{125}$ I seed implantation alone was 7 months. Du et al (30) reported the long-term effect of gemcitabine-combined endoscopic ultrasonography-guided ${ }^{125} \mathrm{I}$ seed implantation in pancreatic cancer. It was demonstrated that the median survival time was 4 months in the seed implantation-only group. The median survival times of the two studies $(11,30)$ described are shorter compared to the results of the present study. These differences may be due to a higher proportion of patients with non-metastatic locally advanced tumors in the present study. 
Table IV. Compliance to questionnaires during the follow-up of patients with locally advanced unresectable pancreatic head carcinoma.

\begin{tabular}{lccc}
\hline & \multicolumn{2}{c}{ No. of patients (\%) } & \\
\cline { 2 - 3 } $\begin{array}{l}\text { Months } \\
\text { following surgery }\end{array}$ & Group A & Group B & P-value \\
\hline Baseline & $34 / 34(100)$ & $32 / 32(100)$ & 0.806 \\
1 & $30 / 34(88)$ & $27 / 32(84)$ & 0.122 \\
3 & $32 / 34(94)$ & $24 / 28(86)$ & 0.233 \\
6 & $25 / 33(76)$ & $13 / 18(72)$ & 0.955 \\
9 & $19 / 24(79)$ & $5 / 8(63)$ & 0.116 \\
12 & $12 / 17(71)$ & $3 / 6(50)$ & 0.621 \\
\hline
\end{tabular}

Group A patients underwent a combination of surgical bypass (biliary and gastric bypass) and permanent Iodine-125 seed implantation whereas patients in group B underwent biliary and gastric bypass only.

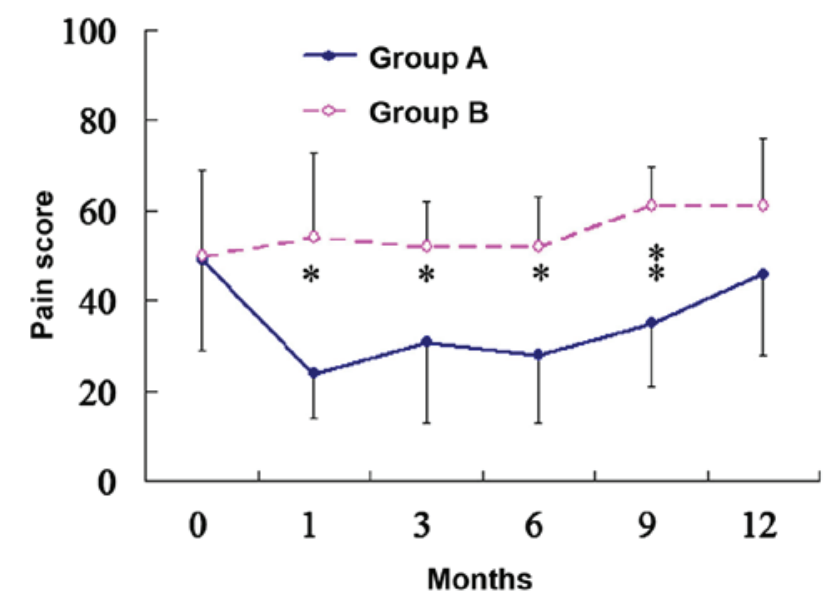

Figure 3. Comparison of pain scores between two groups of patients with locally advanced unresectable pancreatic head carcinoma. Statistical significance are indicated as ${ }^{*} \mathrm{P}<0.001$ and ${ }^{* *} \mathrm{P}=0.006$. Error bars indicate standard deviation. Group A patients underwent a combination of surgical bypass (biliary and gastric bypass) and permanent Iodine-125 seed implantation whereas patients in group B underwent biliary and gastric bypass only.

The aim of treatment for patients with unresectable pancreatic cancer is to improve the quality of their remaining life (31). In the present study, the physical function and global health status were demonstrated to decrease following surgery in the two groups. The scores recovered to preoperative levels of QOL within 3 months following surgery. The only exception was global health status, which remained stable in group B. On the symptom scale, digestive symptoms worsened in the two groups. This result may be attributed to: The reconstruction of the digestive tract changes the normal anatomy of upper gut; and/or the radiation of ${ }^{125} \mathrm{I}$ seeds having a negative effect on adjacent organs.

In the present study, a pain score was calculated using a visual analog scale of pain, frequency of pain attacks and pain-associated sick leave. In addition, analgesic medication was applied to quantify pain intensity more distinctly. It was demonstrated that ${ }^{125} \mathrm{I}$ seeds implantation resulted in more precise pain relief.

With the development of therapeutic methods, biliary and digestive stenoses can be endoscopically treated in patients with unresectable pancreatic cancer. However, Ueda et al (32) compared palliative surgical biliary bypass to endoscopic biliary stenting for unresectable pancreatic cancer, whereby a lower morbidity, lower mortality and more effective long-term palliation was demonstrated in the surgical biliary bypass group. Prophylactic surgical biliary bypass with gastrointestinal bypass may be a good treatment option for non-jaundiced patients undergoing chemotherapy for unresectable pancreatic cancer. Randomized controlled trials have shown prophylactic gastrojejunostomy to significantly decrease the incidence rate of late gastric outlet obstruction without altering the postoperative mortality or morbidity rates, or prolonging hospital stay compared to biliary bypass alone (24,33). Mann et al (34) demonstrated that surgical combined biliary and gastric bypass offers effective long-term palliation of biliary and gastric outlet obstruction in patients with unresectable malignant disease. Low mortality and morbidity rates suggest that this should be used as a first line therapy in patients who are considered unresectable at laparotomy.

In conclusion, the results of the present study suggest that brachytherapy using ${ }^{125} \mathrm{I}$ seed implantation is feasible, safe and effective for the treatment of patients with unresectable pancreatic cancer. Brachytherapy using ${ }^{125}$ I seed implantation provides satisfactory QOL and produces adequate pain relief.

\section{References}

1. Siegel R, Ma J, Zou Z and Jemal A: Cancer statistics, 2014. CA Cancer J Clin 64: 9-29, 2014.

2. von Wichert G, Seufferlein T and Adler G: Palliative treatment of pancreatic cancer. J Dig Dis 9: 1-7, 2008.

3. Le Pimpec Barthes F, Chapuis O, Riquet M, Cuttat JF, Peillon C, Mouroux J and Jancovici R: Thoracoscopic splanchnicectomy for control of intractable pain in pancreatic cancer. Ann Thorac Surg 65: 810-813, 1998.

4. Isla AM, Worthington T, Kakkar AK and Williamson RC: A continuing role for surgical bypass in the palliative treatment of pancreatic carcinoma. Dig Surg 17: 143-146, 2000.

5. Handley WS: Pancreatic cancer and the treatment by implanted radium. Ann Surg 100: 215-222, 1934.

6. Hilaris B and Rousiss K: Cancer of the pancreas. In: Hilaris BS, edition. Handbook of interstitial brachytherapy. Acton, Mass: Publishing Sciences Group (PSG), 251-262, 1975.

7. Syed AM, Puthawala AA and Neblett DL: Interstitial iodine-125 implant in the management of unresectable pancreatic carcinoma. Cancer 52: 808-813, 1983.

8. Wang J, Jiang Y, Li J, Tian S, Ran W and Xiu D: Intraoperative ultrasound-guided iodine-125 seed implantation for unresectable pancreatic carcinoma. J Exp Clin Cancer Res 28: 88, 2009.

9. Whittington R, Solin L, Mohiuddin M, Cantor RI, Rosato FE, Biermann WA, Weiss SM and Pajak TF: Multimodality therapy of localized unresectable pancreatic adenocarcinoma. Cancer 54: 1991-1998, 1984.

10. Zhongmin W, Yu L, Fenju L, Kemin C and Gang H: Clinical efficacy of CT-guided iodine-125 seed implantation therapy in patients with advanced pancreatic cancer. Eur Radiol 20: 1786-1791, 2010

11. Wang H, Wang J, Jiang Y, Li J, Tian S, Ran W, Xiu D and Gao Y: The investigation of $125 \mathrm{I}$ seed implantation as a salvage modality for unresectable pancreatic carcinoma. J Exp Clin Cancer Res 32: 106, 2013.

12. Yates JW, Chalmer B and Mckegney FP: Evaluation of patients with advanced cancer using the karnofsky performance status. Cancer 45: 2220-2224, 1980. 
13. Verslype C, Van Cutsem E, Dicato M, Cascinu S, Cunningham D, Diaz-Rubio E, Glimelius B, Haller D, Haustermans K, Heinemann $\mathrm{V}$, et al: The management of pancreatic cancer. Current expert opinion and recommendations derived from the 8th World congress on gastrointestinal cancer, Barcelona, 2006. Ann Oncol 18 (Suppl 7): viil-vii10, 2007.

14. Banks PA, Bollen TL, Dervenis C, Gooszen HG, Johnson CD, Sarr MG, Tsiotos GG and Vege SS; Acute Pancreatitis Classification Working Group: Classification of acute pancreatitis-2012: Revision of the Atlanta classification and definitions by international consensus. Gut 62: 102-111, 2013.

15. Bassi C, Dervenis C, Butturini G, Fingerhut A, Yeo C, Izbicki J, Neoptolemos J, Sarr M, Traverso W and Buchler M; International Study Group on Pancreatic Fistula Definition: Postoperative pancreatic fistula: An international study group (ISGPF) definition. Surgery 138: 8-13, 2005.

16. Murakami Y, Uemura K, Hayashidani Y, Sudo T, Hashimoto Y, Nakagawa N, Ohge H and Sueda T: No mortality after 150 consecutive pancreatoduodenctomies with duct-to-mucosa pancreaticogastrostomy. J Surg Oncol 97: 205-209, 2008.

17. Park YC, Kim SW, Jang JY, Ahn YJ and Park YH: Factors influencing delayed gastric emptying after pylorus-preserving pancreatoduodenectomy. J Am Coll Surg 196: 859-865, 2003.

18. Bodner WR and Hilaris BS: Brachytherapy and pancreatic cancer. Semin Surg Oncol 13: 204-207, 1997.

19. Monk BJ, Tewari KS, Puthawala AA, Syed Am, Haugen JA and Burger RA: Treatment of recurrent gynecologic malignancies with iodine-125 permanent interstitial irradiation. Int J Radiat Oncol Biol Phys 52: 806-815, 2002.

20. Dobelbower RR Jr, Merrick HW III, Ahuja RK and Skeel RT: 125I interstitial implant, precision high-dose external beam therapy, and 5-FU for unresectable adenocarcinoma of pancreas and extrahepatic biliary tree. Cancer 58: 2185-2195, 1986.

21. Miller AB, Hoogstraten B, Staquet M and Winkler A: Reporting results of cancer treatment. Cancer 47: 207-214, 1981.

22. Aaronson NK, Ahmedzai S, Bergman B, Bullinger M, Cull A, Duez NJ, Filiberti A, Flechtner H, Fleishman SB, de Haes JC, et al: The European Organization for Research and Treatment of Cancer QLQ-C30: A quality-of-life instrument for use in international clinical trials in oncology. J Natl Cancer Inst 85: 365-376, 1993.

23. Zhao $\mathrm{H}$ and Kanda K: Testing psychometric properties of the standard Chinese version of the European Organization for Research and Treatment of Cancer Quality of Life Core Questionnaire 30 (EORTC QLQ-C30). J Epidemiol 14 193-203, 2004.
24. Van Heek NT, De Castro SM, van Eijck CH, van Geenen RC, Hesselink EJ, Breslau PJ, Tran TC, Kazemier G, Visser MR, Busch OR, et al: The need for a prophylactic gastrojejunostomy for unresectable periampullary cancer: A prospective randomizedmulticenter trial with special focus on assessment of quality of life. Ann Surg 238: 894-905, 2003.

25. Bloechle C, Izbicki JR, Knoefel WT, Kuechler T and Broelsch CE: Quality of life in chronic pancreatitis: Results after duodenum-preserving resection of the head of the pancreas. Pancreas 11: 77-85, 1995.

26. Ma JX, Jin ZD, Si PR, Liu Y, Lu Z, Wu HY, Pan X, Wang LW, Gong YF, Gao J and Zhao-shen L: Continuous and low-energy 125I seed irradiation changes DNA methyltransferases expression patterns and inhibits pancreatic cancer tumor growth J Exp Clin Cancer Res 30: 35, 2011.

27. Zou YP, Li WM, Zheng F, Li FC, Huang H, Du JD and Liu HR Intraoperative radiofrequency ablation combined with 125 iodine seed implantation for unresectable pancreatic cancer. World J Gastroenterol 16: 5104-5110, 2010.

28. Jin Z, Du Y, Li Z, Jiang Y, Chen J and Liu Y: Endoscopic ultrasonography-guided interstitial implantation of iodine 125 -seeds combined with chemotherapy in the treatment of unresectable pancreatic carcinoma: a prospective pilot study. Endoscopy 40: 314-320, 2008.

29. Freelove R and Walling AD: Pancreatic cancer: Diagnosis and management. Am Fam Physician 73: 485-492, 2006.

30. Du Y, Jin Z, Meng H, Zou D, Chen J, Liu Y, Zhan X, Wang D, Liao Z and Li Z: Long-term effect of gemcitabine-combined endoscopic ultrasonography-guided brachytherapy in pancreatic cancer. J Interv Gastroenterol 3: 18-24, 2013.

31. Kostro J and Sledziński Z: Quality of life after surgical treatment of pancreatic cancer. Acta Chir Belg 108: 679-684, 2008.

32. Ueda J, Kayashima T, Mori Y, Ohtsuka T, Takahata S, Nakamura $M$ and Tanaka M: Hepaticocholecystojejunostomy as effective palliative biliary bypass for unresectable pancreatic cancer. Hepatogastroenterology 61: 197-202, 2014.

33. Lillemoe KD, Cameron JL, Hardacre JM, Sohn TA, Sauter PK, Coleman J, Pitt HA and Yeo CJ: Is prophylactic gastrojejunostomy indicated for unresectable periampullary carcinoma? A prospective randomized trial. Ann Surg 230: 322-330, 1999.

34. Mann CD, Thomasset SC, Johnson NA, Garcea G, Neal CP, Dennison AR and Berry DP: Combined biliary and gastric bypass procedures as effective palliation for unresectable malignant disease. ANZ J Surg 79: 471-475, 2009. 